\title{
Toxic effects of UV filters from sunscreens on coral reefs revisited: regulatory aspects for "reef safe" products
}

\author{
Ingo B. Miller ${ }^{1 *}$, Sascha Pawlowski ${ }^{2}$, Matthias Y. Kellermann ${ }^{1}$, Mechtild Petersen-Thiery ${ }^{3}$, Mareen Moeller ${ }^{1}$,
} Samuel Nietzer ${ }^{1}$ and Peter J. Schupp ${ }^{1,4^{*}}$

\begin{abstract}
Background: Tropical coral reefs have been recognized for their significant ecological and economical value. However, increasing anthropogenic disturbances have led to progressively declining coral reef ecosystems on a global scale. More recently, several studies implicated UV filters used in sunscreen products to negatively affect corals and possibly contribute to regional trends in coral decline. Following a public debate, bans were implemented on several organic UV filters and sunscreen products in different locations including Hawaii, the U.S. Virgin Islands and Palau. This included banning the widely used oxybenzone and octinoxate, while promoting the use of inorganic filters such as zinc oxide even although their toxicity towards aquatic organisms had been documented previously. The bans of organic UV filters were based on preliminary scientific studies that showed several weaknesses as there is to this point no standardized testing scheme for scleractinian corals. Despite the lack of sound scientific proof, the latter controversial bans have already resulted in the emergence of a new sunscreen market for products claimed to be 'reef safe' (or similar). Thus, a market analysis of'reef safe' sunscreen products was conducted to assess relevant environmental safety aspects of approved UV filters, especially for coral reefs. Further, a scientifically sound decision-making process in a regulatory context is proposed.
\end{abstract}

Results: Our market analysis revealed that about $80 \%$ of surveyed sunscreens contained inorganic UV filters and that there is a variety of unregulated claims being used in the marketing of 'reef safe' products with 'reef friendly' being the most frequently used term. Predominantly, four organic UV filters are used in 'reef safe' sunscreens in the absence of the banned filters oxybenzone and octinoxate. Analysis of safe threshold concentrations for marine water retrieved from existing REACH registration dossiers could currently also safeguard corals.

Conclusion: There is a substantial discrepancy of treatments of organic versus inorganic UV filters in politics as well as in the'reef safe' sunscreen market, which to this point is not scientifically justified. Thus, a risk-based approach with equal consideration of organic and inorganic UV filters is recommended for future regulatory measures as well as a clear definition and regulation of the'reef safe'terminology.

Keywords: Coral toxicity, Ecotoxicology, UV filters, Standardization, Reef safe, Sunscreen, Regulation, Coral reef

*Correspondence: ingo.miller1@uni-oldenburg.de; peter.schupp@unioldenburg.de

${ }^{1}$ Environmental Biochemistry Group, Institute for Chemistry and Biology of the Marine Environment (ICBM), Carl von Ossietzky University of Oldenburg, Schleusenstr. 1, 26382 Wilhelmshaven, Germany Full list of author information is available at the end of the article

\section{Background}

Tropical coral reefs are among the most biodiverse and economically valuable ecosystems on our planet. These complex systems provide a wide range of vital ecosystem services to human societies around the globe through coastal protection, fisheries, tourism and recreation

\section{Springer Open}

(c) The Author(s) 2021. This article is licensed under a Creative Commons Attribution 4.0 International License, which permits use, sharing, adaptation, distribution and reproduction in any medium or format, as long as you give appropriate credit to the original author(s) and the source, provide a link to the Creative Commons licence, and indicate if changes were made. The images or other third party material in this article are included in the article's Creative Commons licence, unless indicated otherwise in a credit line to the material. If material is not included in the article's Creative Commons licence and your intended use is not permitted by statutory regulation or exceeds the permitted use, you will need to obtain permission directly from the copyright holder. To view a copy of this licence, visit http://creativeco mmons.org/licenses/by/4.0/. 
opportunities, as well as resource for natural building materials (i.e., lime stones) and new medicines [5, 55]. Although tropical coral reefs cover less than 0.1 percent of the ocean's surface $[76,77]$, they harbor around onequarter of all known marine species [5]. In particular, tropical hermatypic (reef-building) corals, the actual reef engineers, thrive in oligotrophic waters owing to highly efficient retention and close nutrient cycling by them and other reef organisms $[13,68,71]$. This high productivity within these otherwise unproductive "marine deserts" emphasizes the importance of coral reefs as biodiversity hotspots and high value economic resources for human populations living in their proximity [40].

Despite their ecological and economical importance, coral reefs are declining at a historically unprecedented pace due to multiple local and global stressors that are all caused directly or indirectly by anthropogenic activities $[4,5,42,47]$. These man-made disturbances are quickly progressing, thus pushing coral reefs towards the tipping point of functional collapse [41, 45, 48, 70]. As a key driver of climate change, excessive emissions of fossil organic carbon into the atmosphere have been leading to a steady increase of sea surface temperatures [49]. Already, several major global mass bleaching events have occurred in tropical coral reef areas around the world starting in the 1980s [37]. Such mass bleaching events have become more frequently, resulting even in recurrent year to year mass bleaching events as observed in 1998, 2002 and 2016 [43, 47]. The latest widespread bleaching event occurred in 2020 at the world's largest contiguous coral reef, the Great Barrier Reef (AIMS [1]). Thus, immediate and rapid action to reduce global warming is needed to secure the future of tropical coral reefs [42, 47].

However, on a local scale, more than $60 \%$ of the world's reefs are threatened by one or several man-made disturbances with overfishing being the most ubiquitous immediate pressure [5]. Other local perturbations such as destructive fishing, watershed-based pollution, marinebased pollution and damage from ships and coastal development, including associated sedimentation, also pose direct and immediate threats to coral reefs [5, 56]. Given the multitude of stressors and threats, some authors suggest that besides trying to achieve global scale measures, local actions should be taken into account to minimize the impact on coral reefs as this may even contribute to the overall resilience towards mass bleaching events [2, 3, 32, 42, 44, 46, 47, 72, 87].

Recent research indicates that some ultraviolet (UV) filters used in sunscreens and other personal care products (PCPs) may impact coral health on a local scale. Some researchers have claimed negative health effects, bleaching and enhanced mortality after exposure of corals to several widely used UV filters $[10,12,16,17$, $28,34,51,74,78,79,90]$. Following media driven public attention gained from the findings of Danovaro et al. [12] and particularly from those of Downs and colleagues $[16,17]$, Hawaii was the first state (followed by other states and nations) to take legislative action to ban (as of January 2021) two organic UV filters commonly used in sunscreens: benzophenone-3 (BP3 also known as oxybenzone) and ethylhexyl methoxycinnamate (EHMC or octinoxate) [33]. On the other hand, inorganic UV filters such as zinc oxide $(\mathrm{ZnO})$, known to be very toxic to aquatic life [18] (including cnidaria with a no observed effect concentration (NOEC) of $300 \mu \mathrm{g} \mathrm{Zn}^{2+} \mathrm{L}^{-1}$ ), are still allowed to be used in these locations.

However, sunscreens and the UV filters within are part of human sun protection measures to shield human skin from harmful UV-A (315-400 nm) and UV-B (280-315 nm) radiation that are well-known causes for sunburn, skin aging and skin cancer [6, 30, 61]. As ingredients of personal care products, the number of UV filters is highly regulated and limited by various national legislations. For example, prior to marketing in the EU an UV filter used as cosmetic ingredient requires the positive assessment by the independent EU advisory Scientific Committee for Consumer Safety (SCCS). The positive evaluation is typically followed by an approval by the EU Commission leading to an inclusion of the assessed filter into the respective annex allowing the use in the EU. Currently, $29 \mathrm{UV}$ filters meet the requirements for being used in cosmetic products [24] (cf. Additional file 1: Table S1). In the United States, sunscreen products are classified as over-the-counter (OTC) products and are strictly regulated by the US Food and Drug Administration (FDA) according to pharma requirements. Thus, only 16 UV filters are currently allowed [82, 84, 85]. Because of these stringent requirements by US legislation, no approval of any new UV filter has been granted and consequently listed in the monograph since 1998. Owing to their high complexity in sunscreen and cosmetic products, substituting one UV filter with another is challenging since not all UV filters are compatible with each other and a combination of several UV filters is required to reach sufficient broad spectrum protection as well as a high sun protection factor (SPF; [66, 75]).

Therefore, regulatory measures should be evaluated thoroughly and should be based on actual evidence before legislative action is implemented. In fact, the passed sunscreen bans are considered as controversial, since on the one hand corals are difficult to culture organisms and on the other UV filters are difficult test substances [56, 59, 64], leading to a potentially high variability in possible test results if the test procedure does not follow a standardized testing protocol. Therefore, some of the reported 
UV filter toxicity data for corals should be taken with caution. Thus, further exploration using standardized and validated testing methods to avoid both false positive and false negative test results is required [54, 56, 75]. Data from such standardized toxicity tests could then be used as the basis for further regulatory action. For a detailed review on ecotoxicological studies of UV filters on corals and a discussion on the need for standardized coral toxicity testing, see Moeller et al. [56].

Nevertheless, the public debate on UV filter bans has already influenced marketing strategies of various sunscreen labels in a way that several products are currently marketed as 'reef safe' (or similar), even though such marketing claims may lack sound scientific proof [50, 56]. Within this article, relevant environmental aspects of approved UV filters and its safety for the marine environment (i.e., corals and coral reefs) are evaluated and a proposal for a scientifically sound decision-making process in a regulatory context is discussed.

\section{Methods}

\section{UV filter bans}

The current state of UV filter bans was reviewed by an online search using the terms 'UV filter ban' AND 'sunscreen ban' in different search engines such as Google [31], Ecosia [23] and metaGer [52]. The online search was conducted between January 11 and February 12, 2021.

Details about specific bans were compiled from the respective legislative documents as outlined in the result sections.

\section{Market analysis of reef-safe sunscreens}

To give further insights in marketing strategies, we conducted a web-based analysis on sunscreens that were marketed as 'reef safe' around the globe. To do so, the terms 'sunscreen' AND 'reef safe' AND 'reef friendly' AND 'coral safe' AND 'marine safe' were used in different search engines such as Google [31], Ecosia [23] and metaGer [52], to search the web for products using those terms. Subsequently, the product websites were screened for marketing claims as well as the used UV filters in the particular sunscreen product. Additionally, the DailyMed database [58] was used for information about product ingredients. The online search was conducted between February 1 and March 11, 2021.

\section{Comparable aquatic toxicity}

UV filters require approval from the SCCS before they can be used in cosmetic products. Furthermore, a registration as a chemical under the EU REACH legislation is needed to address potential concerns related to worker and environmental safety. Thus, for each substance a vast amount of related information is required to allow for a proper hazard and risk assessment. In order to make this process transparent, available data are published by the European Chemicals Agency (ECHA) via their webpage [19] and can be used for a comparative environmental assessment of the UV filters registered within the EU. Since these data sets are in some cases extremely data rich (i.e., $\mathrm{ZnO}$ ), we focused in our analysis on the most sensitive taxonomic species and the predicted no effect concentration for marine water $\left(\mathrm{PNEC}_{\text {marine water }}\right)$. These values were then compared with results from available scientific literature, investigating the in vivo toxicity of corals. Again, we only considered results from the most sensitive species for the comparative assessment. This procedure allowed for a worst-case comparison between the existing data sets according to the REACH registration dossiers of the individual substances and the coral toxicity data from recent literature studies.

\section{Results}

\section{UV filter bans used in sunscreens}

Following a large public debate in the media about the ramifications of an influx of active sunscreen ingredients on coral reefs, Hawaii was the first state that took regulatory actions to ban the sale of sunscreen products containing BP3 and/or EHMC [33]. The bill was passed by the Senate of Hawaii in 2018 and formally took effect in January 2021. Education and outreach campaigns, as well as widespread news coverage already raised public awareness about the potential negative effects of sunscreen products on coral reefs prior to the ban [50]. Other states and nations followed Hawaii's example and prohibited the same but also further organic UV filters (see Table 1 for summary). For example, the Republic of Palau was

Table 1 Locations that took regulatory measures to ban certain organic UV filters

\begin{tabular}{llll}
\hline Location & Banned UV filter & Effective as of & Reference \\
\hline Hawaii & BP3 & January 2021 & {$[33]$} \\
Palau & EHMC & January 2020 & {$[69]$} \\
& BP3 & & \\
& EHMC & & \\
& OCR & & \\
U.S. Virgin Islands & BMBC & March 2020 & {$[86]$} \\
& EHMC & & \\
Aruba & OCR & July 2020 & {$[14]$} \\
Bonaire & BP3 & & {$[53]$} \\
& BP3 & January 2021 & {$[57]$} \\
Key West Florida & BP3 & & \\
& EHMC & January 2021 & {$[7]^{\mathrm{a}}$}
\end{tabular}

${ }^{a}$ City of Key West's vote was later overruled by the state of Florida bill SB 172 , preempting such regulatory decisions to the state only $[29,80]$ 
the first nation to pass a bill to ban certain chemicals that are commonly used in personal care products (PCPs) [69]. Besides BP3 and EHMC two further UV filters, namely octocrylene (OCR) and 4-methylbenzylcathinone $(4 \mathrm{MBC})$ as well as six additional chemicals used as fungal- or microbial agents and preservatives were banned since January 2020. The regulatory decision was based on a report on the sunscreen pollution analysis in Palau's Jellyfish Lake conducted by the Coral Reef Research Foundation [9]. The parliament of the Caribbean island nation Aruba prohibited among other products, the import, sale, production and distribution of sunscreen products containing oxybenzone effective since July 1 , $2020[14,53]$. Another constituent island nation of the Netherlands, Bonaire, also approved a motion to prohibit sunscreens containing BP3 and EHMC came also into effect in January 2021 [57]. Also, some nature reserves in Mexico have approved bans [57]. For example, visitors of a water park in Xel-Ha (Mexico) are encouraged to swap out their sunscreen for an ecofriendly biodegradable option [62, 73]. Furthermore, US National Park Services lecture their visitors about the impacts of sunscreens on corals and encourages the use of mineral-based (inorganic) sunscreens [73]. According to Narla and Lim [57], similar bans are being actively discussed in the European Union as well as in Brazil.

A somewhat different situation developed in Florida (USA), where the Key West jurisdiction passed a bill prohibiting the sale of sunscreens that contained the active ingredients BP3 and EHMC in 2019 [7]. However, the same bill, which would also had gone into effect in January 2021, was later overruled (bill SB 172) by the state of Florida [29, 80]. Lawmakers argued that the scientific proof to ban certain UV filters in sunscreens was insufficient. Furthermore, the states' bill prohibits local legislation to ban over-the-counter (OTC) drugs such as sunscreens, confining such decisions only to the state.

Whereas within the EU the number of approved UV filters is considered as still sufficient to compose suitable sunscreen formulations for the global sunscreen market, certain national restrictions impact the number of approved UV filters. In fact, the ban of two widely used UV filters in some US states limits the number of globally approved filters down to eight. One may consider this number still as sufficient, however, it should be taken into account that differences in photochemical stability and other physico-chemical properties such as water and/or oil solubility limits the possibility to compose applicable UV filter compositions ( $c f$. Sohn et al. [75] for details).

\section{Reef-safe sunscreen claims}

Following the public debate and the implementation of sunscreen bans, consumers are progressively concerned about the potential impacts their sunscreen products may have on the coral environment [50]. Consequently, several cosmetic manufacturers have already acted on these concerns by incorporating claims such as 'reef safe' or 'reef friendly' into the marketing strategies of their sunscreen products. According to a survey conducted by Levine [50] in Hawaii, a vast majority of people are willing to purchase sunscreens labeled to be harmless for coral reef environments.

Our search resulted in a total of 62 sunscreen products claiming 'reef safe' or 'reef friendly' properties ( $c f$. Fig. 1). Detailed results for each product are presented in the supplements (Additional file 1: Table S2). It should be noted at this point that the results of our web search can only provide a snapshot of available products on the market as it is impossible to find all reef-safe marketed sunscreen products available around the world. However, this analysis provides an overview of the 'reef safe' sunscreen industry that has recently evolved, the UV filters they use and the claims they make, and thus, sheds some light on issues that came along with preliminary scientific findings and unsound regulatory measures.

The web-based analysis revealed that the majority $(79 \%, n=49)$ of the sunscreens marketed as "reef safe" contained inorganic (or mineral) UV filters only, while $21 \%$ of the products used organic (or chemical) UV filters in their formulations $(n=13)$.

Different labels or claims are being used to promote that products are safe to use on coral reefs. 'Reef friendly' and 'reef safe' were the most frequently used marketing claims with $45 \%$ and $44 \%$ of all products, respectively. One product was advertised as 'coral friendly' and another product as 'coral safe \& reef friendly'. Moreover, two formulators promoted their products as being 'coralreef friendly'. Furthermore, some labels directly referred to the Hawaiian ban [33] with two products being labeled as 'compliant with Hawaii reef bill' and another one claimed to be 'Hawaii safe'. Some of the brands used those claims directly on their products, while others only promoted it on their website. Particularly mineral sunscreen brands often seem environmentally conscious and offer educational material on their platforms informing their customers about the impacts of organic UV filters (i.e., oxybenzone) on coral reefs referring to scientific findings. The term 'oxybenzone free' is also often found additionally on the products' packaging or on the label' websites for both, organic and inorganic sunscreen products. For this article, we will collectively use 'reef safe' as a representative term for the above-mentioned claims.

About one-fifth of the 'reef safe' marketed sunscreens used a range of 9 different organic UV filters for their filter system. In $92 \%$ of the 'reef safe' sunscreens with organic filters were butyl methoxydibenzoylmethane 
a)

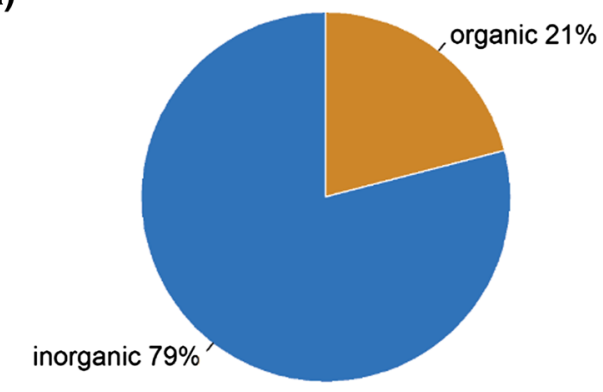

c)

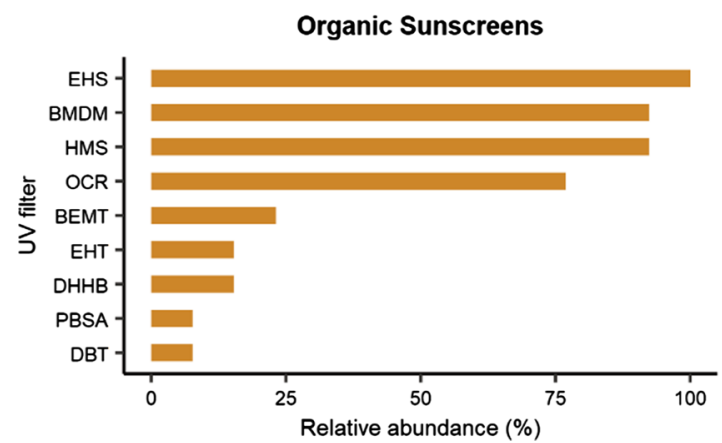

b)

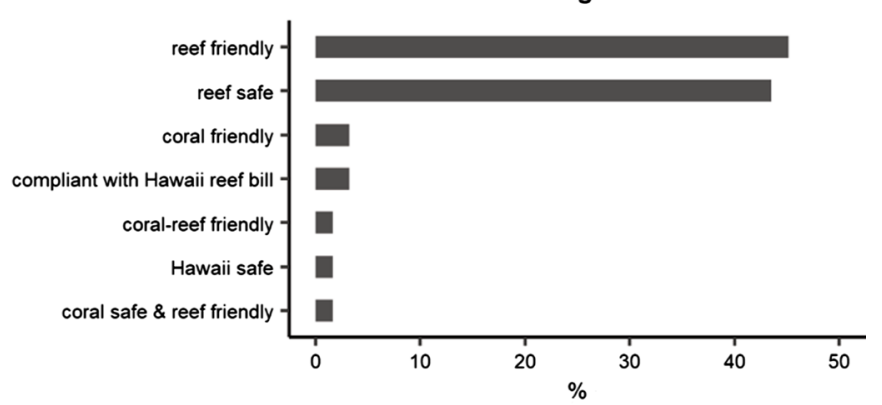

d)

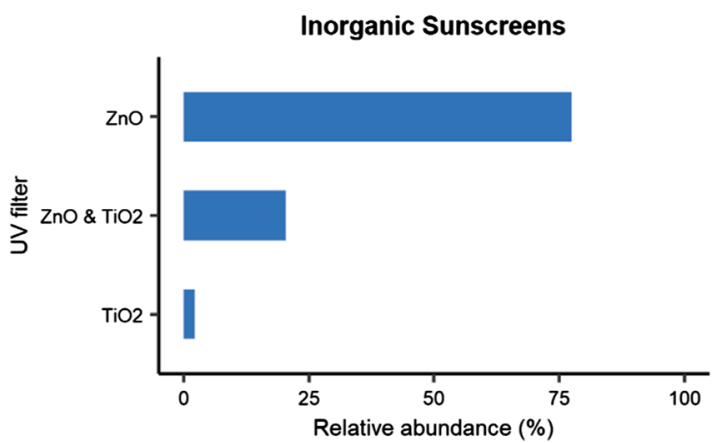

Fig. 1 Results of web-based analysis of'reef safe' marketed sunscreens ( $n=62$ products). a Relative abundance of all UV filter types found; $\mathbf{b}$ marketing claims associated with the identified products; $\mathbf{c}$ relative abundance of organic UV filters used in chemical reef-safe sunscreens; $\mathbf{d}$ relative abundance of inorganic UV filters used in mineral reef-safe sunscreens. The here used chemical abbreviations are further explained in Table S1 or list of abbreviations

(BMDM or avobenzone) and homomethyl salicylate (HMS or homosalate) the active ingredients, while ethylhexyl salicylate (EHS or octisalate) was present in all of the organic sunscreens. OCR was used additionally in $77 \%$ of the investigated products (Fig. 1c). Less than one-quarter of surveyed products contained either PBSA (8\%), BEMT (23\%), EHT (15\%), DHHB (15\%) and DBT $(8 \%)$ in various combinations with the before mentioned filters. Interestingly, the latter four are allowed in the EU but not in the US ( $c f$. Additional file 1: Table S1).

About three quarters (78\%) of all surveyed 'reef safe' inorganic sunscreens $(n=49)$ used $\mathrm{ZnO}$ as the single active ingredient to reach broad spectrum UV protection (Fig. 1d), while one product contained $\mathrm{TiO}_{2}$ as active ingredient only. A combination of the latter two inorganic UV filters was declared in one-fifth of the inorganic sunscreen products.

\section{Comparable aquatic toxicity and impact on the $\mathrm{PNEC}_{\text {marine }}$}

water

UV filters can be organic or inorganic. In any case, the absorption of UV light is for both "classes" of chemicals similarly obtained by shifting pi-electrons into an excited energy level [38]. In principle, when these excited electrons return to their basic energy level, the UV-filters transform high energy and thus harmful UV light into harmless heat. Particulate UV filters, like the inorganic mineral-based filters, but also some organic UV filters, add another boosting feature to the profile by reflecting and/or scattering the light, which increases the efficacy [39]. Thus, inorganic UV filters must be semiconductors (or conductors) to have the option of electron transfer in an additional energy level [8]. This is the case for $\mathrm{TiO}_{2}$ and $\mathrm{ZnO}$. Beside the transformation into heat, for inorganic UV filters also photocatalytic activity is described which may lead to the formation of toxic ozone [67]. Organic UV filters have as common chemical feature one or several conjugated double bonds. Therefore, individual chemical structures can differ significantly, resulting in different physico-chemical properties. For example, there are well water-soluble filters such as terephthalylidene dicamphor sulfonic acid (TDSA) (water solubility of $600 \mathrm{~g} \mathrm{~L}^{-1}$ ), but there are also poorly water-soluble ones like bis-ethylhexyloxyphenol methoxyphenyl triazine (BEMT) with a solubility of only $4.5 \mathrm{ng} \mathrm{L}^{-1}$ (cf. Table 2 ). Whereas the majority lacks sufficient biodegradation in the environment, some UV filters such as EHMC may 
Table 2 Overview of UV filters, associated water solubility, environmental classification, ecotoxicological threshold levels and derived $\mathrm{PNEC}_{\text {marine water }}$

\begin{tabular}{|c|c|c|c|c|c|c|c|c|}
\hline \multirow[t]{2}{*}{ UV filter ${ }^{a}$} & \multirow{2}{*}{$\begin{array}{l}\text { Water } \\
\text { solubility } \\
\left(\mu \mathrm{g} \mathrm{L}^{-1}\right)^{\mathrm{b}}\end{array}$} & \multirow{2}{*}{$\begin{array}{l}\text { Environmental } \\
\text { GHS } \\
\text { classification }\end{array}$} & \multicolumn{5}{|l|}{ Freshwater $^{b}$} & \multirow{2}{*}{$\begin{array}{l}\text { Seawater } \\
\text { PNEC }_{\text {marine water }} \\
\left(\mu \mathrm{g} \mathrm{L}^{-1}\right)^{\mathrm{b}}\end{array}$} \\
\hline & & & $\begin{array}{l}\text { Most sensitive } \\
\text { species } \\
\text { (taxonomic } \\
\text { group) }^{\mathrm{b}}\end{array}$ & Effect level & $\begin{array}{l}\text { Test duration } \\
\text { (d) }\end{array}$ & Value $\left(\mu \mathrm{g} \mathrm{L}^{-1}\right)$ & $\begin{array}{l}\text { Assessment } \\
\text { factor }\end{array}$ & \\
\hline $4 \mathrm{MBC}$ & $1.1 \times 10^{3}$ & $\begin{array}{l}\text { Aquatic acute } \\
1 \text { Aquatic } \\
\text { Chronic } 1\end{array}$ & $\begin{array}{c}\text { Daphnia magna } \\
\text { (crustacea) }\end{array}$ & NOEC & 21 & 20 & 500 & 0.04 \\
\hline BP3 & $6 \times 10^{3}$ & $\begin{array}{c}\text { Aquatic Acute } \\
1 \text { Aquatic } \\
\text { Chronic } 2\end{array}$ & $\begin{array}{l}\text { Pseudokirchneri- } \\
\text { ella subcapitata } \\
\text { (green algae) }\end{array}$ & $\mathrm{EC}_{50} / \mathrm{NOEC}$ & $3 / 3$ & $670 / 180$ & 10,000 & 0.067 \\
\hline BP4 & $3 \times 10^{8}$ & Not classified & $\begin{array}{l}\text { Pimephales } \\
\text { promelas (fish) }\end{array}$ & NOEC & 14 & 4895 & 500 & 9.79 \\
\hline BEMT & $4.5 \times 10^{-3}$ & Not classified & $\begin{array}{l}\text { No hazard iden- } \\
\text { tified }\end{array}$ & NOEC & Not applicable & $\geq W S$ & Not applicable & $\begin{array}{l}\text { No hazard } \\
\text { identified }\end{array}$ \\
\hline DBT & $<0^{c}$ & Not classified & $\begin{array}{l}\text { No hazard iden- } \\
\text { tified }\end{array}$ & NOEC & Not applicable & $\geq W S$ & Not applicable & $\begin{array}{l}\text { No hazard } \\
\text { identified }\end{array}$ \\
\hline EHT & $<1$ & Not classified & $\begin{array}{l}\text { No hazard iden- } \\
\text { tified }\end{array}$ & NOEC & Not applicable & $\geq W S$ & Not applicable & $\begin{array}{l}\text { No hazard } \\
\text { identified }\end{array}$ \\
\hline TDSA & $\geq 6 \times 10^{8}$ & Not classified & $\begin{array}{l}\text { No hazard iden- } \\
\text { tified }\end{array}$ & NOEC & Not applicable & $\geq 100 \times 10^{3}$ & Not applicable & $\begin{array}{l}\text { No hazard } \\
\text { identified }\end{array}$ \\
\hline DTS & No data & No data & No data & No data & No data & No data & Not applicable & No data \\
\hline BMDM & 27 & Not classified & $\begin{array}{l}\text { No hazard iden- } \\
\text { tified }\end{array}$ & NOEC & Not applicable & $\geq W S$ & Not applicable & $\begin{array}{l}\text { No hazard } \\
\text { identified }\end{array}$ \\
\hline EHMC & 51 & $\begin{array}{l}\text { Aquatic Chronic } \\
2\end{array}$ & Danio rerio (fish) & NOEC & 30 & 30 & 100 & 0.3 \\
\hline EHS & 500 & Not classified & $\begin{array}{l}\text { No hazard iden- } \\
\text { tified }\end{array}$ & NOEC & Not applicable & $\geq W S$ & Not applicable & $\begin{array}{l}\text { No hazard } \\
\text { identified }\end{array}$ \\
\hline HMS & 400 & Not classified & $\begin{array}{l}\text { No hazard iden- } \\
\text { tified }\end{array}$ & NOEC & Not applicable & $\geq W S$ & Not applicable & $\begin{array}{l}\text { No hazard } \\
\text { identified }\end{array}$ \\
\hline MBBT & $<5 \times 10^{-3}$ & $\begin{array}{l}\text { Aquatic Chronic } \\
4\end{array}$ & $\begin{array}{l}\text { No hazard iden- } \\
\text { tified }\end{array}$ & NOEC & Not applicable & $\geq W S$ & Not applicable & $\begin{array}{l}\text { No hazard } \\
\text { identified }\end{array}$ \\
\hline OCR & 40 & $\begin{array}{l}\text { Aquatic Chronic } \\
1\end{array}$ & $\begin{array}{l}\text { Daphnia magna } \\
\text { (crustacea) }\end{array}$ & NOEC & 21 & 2.7 & 100 & 0.027 \\
\hline $\mathrm{TiO}_{2}$ & 100 & Not classified & $\begin{array}{l}\text { No hazard iden- } \\
\text { tified }\end{array}$ & NOEC & Not applicable & $\geq W S$ & Not applicable & $\begin{array}{l}\text { No hazard } \\
\text { identified }\end{array}$ \\
\hline $\mathrm{ZnO}$ & $2.9 \times 10^{3}$ & $\begin{array}{l}\text { Aquatic Acute } 1 \\
\text { Aquatic Chronic } \\
1 \text { Environment }\end{array}$ & $\begin{array}{l}\text { Ceramium } \\
\text { tenuicore (red } \\
\text { algae) }\end{array}$ & NOEC & 7 & 7.8 & 1 & $6.1^{d}$ \\
\hline
\end{tabular}

\footnotetext{
${ }^{a}$ Refer to List of abbreviations section and Additional file 1: Table S1 of the supplementary material for full names of abbreviated UV filters

${ }^{b}$ According to ECHA REACH registration dossiers [20]

c Value retrieved from the ECHA website $\left(<0 \mathrm{~g} \mathrm{~L}^{-1}\right)$ does not allow for a more precise value

${ }^{d}$ PNEC $_{\text {marine water }}$ was derived from an Species Sensitivity distribution (SSD) method

$\mathrm{EC}_{50}, 50 \%$ effect concentration; NOEC, no observed effect concentration; PNEC, predicted no effect concentration
}

even be considered as readily biodegradable [20]. The differences in the chemistry lead to significant variability in their aquatic ecotoxicity, and a potential ecotoxic effect does not differentiate between inorganic or organic compounds.

Overall, it should be considered that depending on the availability of data, the observed aquatic toxicity relates either to short-term (acute) or long-term (chronic) exposure. In the acute toxicity scenario, the relevant threshold value is a $50 \%$ effect or lethal concentration (i.e., $\mathrm{EC}_{50} /$ $\mathrm{LC}_{50}$ ), in the latter one (chronic toxicity exposure), the no observed effect concentration (NOEC) is considered as adequate for determining the predicted no effect concentration for marine water ( $\mathrm{PNEC}_{\text {marine water }}$ ). The $\mathrm{EC}_{50}$ / $\mathrm{LC}_{50}$ values are typically derived by regression-based interpolation, while NOEC values are based on a tested concentration [60]. As the prediction of the $\mathrm{PNEC}_{\text {marine }}$ water becomes more accurate with the availability of 
long-term toxicity test data, the value of the applied assessment factor (AF) can be reduced. In fact, in cases where only acute data are available, an assessment factor of 10,000 is applied to the $\mathrm{EC} / \mathrm{LC}_{50}$ value $[21,25,65]$. On the other hand, dependent on the number of available chronic toxicity data an AF in the range of 1000 to 100 will be applied to the NOEC value. In rare cases, where the number of data and the range of species/taxonomic groups tested is sufficient (i.e., at least 8 chronic toxicity tests representing various trophic levels and taxonomic groups), a species sensitivity distribution (SSD) may be applied by reducing the AF in the range between 5 and 1 $[21,25,65]$. In any case, the size of the AF used takes into account existing differences in the available data, allowing for a derived $\mathrm{PNEC}_{\text {marine water }}$ considered as being protective for other taxa, such as corals that have not been tested.

As summarized in Table 2, the analysis of data from standardized ecotoxicological tests shows that aquatic toxicity of UV filters is not limited to organic UV filters such as $4 \mathrm{MBC}, \mathrm{BP} 3, \mathrm{EHMC}$ or OCR (which are already banned in some locations; Table 1), but also to inorganic ones such as $\mathrm{ZnO}$. In fact, the derived NOECs from chronic freshwater toxicity studies were about 23 , 628, 2.6 and 3.8 times higher for BP3, BP4, 4MBC and EHMC, respectively, than the derived NOEC for $\mathrm{ZnO}$
(NOEC $7.8 \mu \mathrm{g} \mathrm{L}^{-1}$ ), while the derived NOEC for OCR (NOEC $2.7 \mu \mathrm{g} \mathrm{L}^{-1}$ ) was about 3 times below that of $\mathrm{ZnO}$. Due to the large data set related to $\mathrm{ZnO}$, a SSD was applied based on marine algae species, resulting in an AF of 1 which in turn leads to a PNEC $_{\text {marine water }}$ of $6.1 \mu \mathrm{g} \mathrm{L}^{-1}$ [18], whereas for the other four organic UV filters the safe threshold concentration for marine water ranges from 0.027 (OCR) to $9.79 \mu \mathrm{g} \mathrm{L}{ }^{-1}$ (BP4) (Table 2). The differences in the applied AF, however, resulted in a $\mathrm{PNEC}_{\text {marine water }}$ for $\mathrm{ZnO}$, which is much higher, compared to those of $4 \mathrm{MBC}, \mathrm{BP} 3$ and EHMC. For OCR, the resulting $\mathrm{PNEC}_{\text {marine water }}$ was even far below that of $\mathrm{ZnO}$. Again, the purpose of the derived $\mathrm{PNEC}_{\text {marine water }}$ is to cover the uncertainty of a given lab-based result with a single test species and to develop safe concentrations in applications in marine environments. Thus, the results from available coral toxicity studies may then be compared with the determined $\mathrm{PNEC}_{\text {marine water }}$ as retrieved from the REACH registration dossier of the individual UV filters. To evaluate whether the observed toxicity in corals is covered by the derived $\mathrm{PNEC}_{\text {marine }}$ water for the individual UV filters, available derived lowest observed effect concentrations (LOECs) from toxicity tests with corals or coral larvae were used ( $c f$. Table 3). Likewise, the LOEC is based on a tested concentration related to the next higher concentration than

Table 3 Overview of UV filters and most sensitive observed effect levels of existing UV filter coral toxicity studies

\begin{tabular}{|c|c|c|c|c|c|c|}
\hline UV filter ${ }^{a}$ & Species & Life stage & $\begin{array}{l}\text { Test duration } \\
\text { (d) }\end{array}$ & Effect level & Value $\left(\mu \mathrm{g} \mathrm{L}^{-1}\right)$ & Reference \\
\hline $4 \mathrm{MBC}$ & Acroporasp. & Adult & 2 & LOEC & $37 \times 10^{3 b}$ & {$[12]$} \\
\hline BP3 & Stylophora pistillata & Larvae & 1 & $\mathrm{EC}_{50}$ & 17 & {$[17]$} \\
\hline BP4 & Pocillopora damicornis & Larvae/Adult & $14 / 7$ & $\mathrm{EC}_{50} / \mathrm{LOEC}$ & $>1000$ & {$[36]$} \\
\hline BP4 & Seriatopora caliendrum & Larvae/Adult & $14 / 7$ & $\mathrm{EC}_{50} / \mathrm{LOEC}$ & $>1000$ & [36] \\
\hline BEMT & Pocillopora damicornis & Adult & 7 & $\mathrm{EC}_{50} / \mathrm{LOEC}$ & $>1000^{c}$ & [79] \\
\hline DBT & Pocillopora damicornis & Adult & 7 & $\mathrm{EC}_{50} / \mathrm{LOEC}$ & $>1000$ & [79] \\
\hline EHT & Stylophora pistillata & Adult & 35 & LOEC & $>177^{c}$ & {$[28]$} \\
\hline TDSA & Stylophora pistillata & Adult & 35 & LOEC & $>5030$ & {$[28]$} \\
\hline DTS & Stylophora pistillata & Adult & 35 & LOEC & $>480$ & {$[28]$} \\
\hline BMDM & Stylophora pistillata & Adult & 35 & LOEC & $516^{c}$ & [28] \\
\hline EHMC & Seriatopora caliendrum & Adult & 7 & LOEC & 1000 & [35] \\
\hline EHS & Pocillopora damicornis & Adult & 7 & $\mathrm{EC}_{50} / \mathrm{LOEC}$ & $>1000$ & [79] \\
\hline HMS & Pocillopora damicornis & Adult & 7 & $\mathrm{EC}_{50} / \mathrm{LOEC}$ & $>1000$ & [79] \\
\hline MBBT & Pocillopora damicornis & Adult & 7 & $\mathrm{EC}_{50} / \mathrm{LOEC}$ & $>1000^{c}$ & [79] \\
\hline OCR & Stylophora pistillata & Adult & 35 & LOEC & $1318^{c}$ & {$[28]$} \\
\hline $\mathrm{TiO} 2$ & Acroporasp. & Adult & 2 & $\mathrm{EC}_{50} / \mathrm{LOEC}$ & $>6300$ & [10] \\
\hline $\mathrm{ZnO}$ & Stylophora pistillata & Adult & 35 & LOEC & 94 & {$[28]$} \\
\hline
\end{tabular}

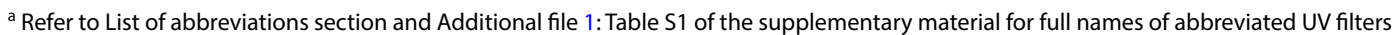

${ }^{b}$ Value recalculated based on $33 \mu \mathrm{L} \mathrm{L}-1$ and a specific density of $1.108 \mathrm{~g} \mathrm{~cm}^{-3}$

'Solvent used; value above known water solubility (WS)

$\mathrm{EC}_{50}, 50 \%$ effect concentration; LOEC, lowest observed effect concentration; n.d., not determined 
the NOEC. However, in this specific case, the LOECs were used despite the observed differences in the exposure times of the corals tested. To allow for a cross comparison of the endpoints, only the most sensitive visible effect on the test organisms such as mortality, bleaching or inhibition of metamorphosis was considered. Based on a recent literature review by Moeller et al. [56] 16 out of 29 within the EU registered filters have been tested in non-standardized coral tests ranging from lab to field conditions. Thus, we focused our comparable toxicity assessment on these substances, of which six (4MBC, BP3, EHMC, methylene bis-benzotriazolyl tetramethylbutylphenol (MBBT), OCR, $\mathrm{ZnO}, c f$. Table 3) are already classified and labeled for the environment according to the Global Harmonized System within the European Union (GHS EU), while one (drometrizole trisiloxane, DTS) lacks any aquatic toxicity data from standardized tests [20]. Five out of six UV filters, namely, 4MBC, BP3, EHMC, OCR and $\mathrm{ZnO}$ were acute and/or chronically toxic to aquatic organisms, while MBBT revealed no acute or chronic toxicity in any aquatic tests available. However, MBBT still falls into the "Aquatic Chronic 4" safety category ("may cause long-term toxicity towards aquatic organisms"), due to the absence of readily biodegradability and due to a high logarithmic octanol-water partition coefficient (log Pow) above four. Interestingly, four UV filters (4MBC, BP3, EHMC, $\mathrm{ZnO}$ ) known to be toxic to aquatic organisms were also considered as toxic to corals, whereas the other two (MBBT and OCR) were tested as being non-toxic up to the highest test concentration or up to the maximum known water solubility ( $c f$. Table 2). For OCR however, no toxicity was observed in corals within the range of its water solubility, although it is known to be toxic to other aquatic organisms such as crustacean (Table 2). Comparing the derived $\mathrm{PNEC}_{\text {marine water }}$ with the observed effect levels (lowest observed effect concentration, LOEC) measured in corals reveals that in all cases, measured toxicity of corals was above the derived PNEC. In fact, for $4 \mathrm{MBC}$ and BP3, derived PNECs for marine water were 0.04 and $0.067 \mu \mathrm{g} \mathrm{L}^{-1}$, respectively, and thus well below the LOECs from coral toxicity tests $\left(37 \mathrm{mg} \mathrm{L}^{-1}\right.$ and $17 \mu \mathrm{g} \mathrm{L}^{-1}$, respectively). However, it should be noted that most coral toxicity studies performed so far lack analytical verification of actual test concentrations and thus, toxicity values may likely be over- or underestimated. Additionally, the range of available coral toxicity data on UV filters consist of both short and long-term toxicity results mainly from adult corals. Only in two cases, coral larvae were assessed $[17,36]$ which makes a cross comparison of UV filters based on these data difficult. Furthermore, there is no standardized test protocol (i.e., using the same test species, test conditions, number of replicates, etc.) available for coral toxicity assays, and the majority of the studies show serious limitations as outlined in recently published literature reviews $[54,56]$.

\section{Discussion}

Our analyses revealed that the existing sunscreen bans so far only focused on organic UV filters and are based on insufficient scientific findings from non-standardized ecotoxicological tests $[54,56]$. These bans on organic UV filters resulted in the emergence of a new sunscreen market in which terms such as 'reef safe' are incorporated as marketing strategies. However, the variety of the different labels and marketing claims used, revealed the regulatory shortcomings in this regard. There is currently no legislation in place that regulates any of the used terms claiming that the said product is safe for corals or the reef environment. There is also no clear definition of 'reef safe' products. However, there seems to be a general consensus among 'reef safe' sunscreen manufacturers and also legislatures that avoiding oxybenzone or octinoxate, the two UV filters first banned in Hawaii [33], in any sunscreen product is equal to being 'reef safe'. Many of the investigated brands defined their understanding of what 'reef safe' actually means in the online presences of the company of the corresponding product or in the FAQ section.

Based on our market analysis, there is a tendency towards the use of inorganic UV filters in so-called 'reef safe' sunscreens. This is probably due to the general belief that inorganic UV filters are, due to their natural origin, safe for the environment. However, in a regulatory context, considering the use of a substance as being safe or not for the environment relies on two basic aspects: (1) the intrinsic hazard profile and (2) the results of an environmental risk assessment (ERA). Whereas the hazard assessment of the individual substance is considered as mandatory in a regulatory context, the latter one may only be required if the data related to both environmental fate and environmental toxicity, revealed that the substance is hazardous towards the environment (see [19, 20, 22]). Taking this into account, our analysis clearly revealed that there are members of both organic (i.e., OCR, EHMC, BP3) and inorganic UV filters (i.e., $\mathrm{ZnO}$ ) that are hazardous to the environment and are classified and labeled according to GHS regulations based on available aquatic toxicity data [81]. Consequently, step 2 (i.e., performing an ERA) will typically follow to evaluate whether the environmental concentrations will surpass the so-called $\mathrm{PNEC}_{\text {marine water }}$ or not. At this stage, however, it has to be acknowledged that the ERA is already part of each REACH registration dossier if an UV filter was identified as hazardous to the environment. 
Nevertheless, ERAs can be either based on annual production volumes (i.e., based on tonnages) or based on application rates (i.e., concentrations used in products and associated release rates). Whereas the first approach relates to percentage-based release rates and thus is strictly correlated to the amount of a substance being produced, the latter one takes much more specific data into account. Risk assessments based on application rates are therefore considered to provide a much more realistic exposure scenario. Those highly sophisticated models exist for the regulation of plant protection and biocidal products [26, 27], but do not yet exist for UV filters used in sunscreens. In other words, such environmental exposure assessments should take into account the direct release of UV filters from the use of sunscreen products into the aquatic environment, which is actually not covered by existing specific environmental release categories (SpERC) provided by the 'The European Cosmetic and Perfumery Association' (Colipa) (Cosmetics [11]). Thus, there is an urgent need to develop such models by the chemical industry, taking substance properties, environmental fate and toxicity aspects into account and relate them to product concentrations, amount of sunscreens applied, number of swimmers, release rates and various local and regional conditions (i.e., current, tidal activities, temperatures).

However, in the absence of such existing models, the analysis of the intrinsic hazardous properties may be regarded as a suitable and practical fallback position to select for the most ecofriendly UV filters [63]. Again, as such hazard property analyses are applicable to both organic and inorganic UV filters, it can be concluded (based on the derived NOEC) that for example $\mathrm{ZnO}$, claimed as a suitable UV filter in 'reef safe' products, is indeed similarly toxic as the banned organic UV filter OCR, and even more toxic than BP3 and EHMC (all of which are banned in some locations; $c f$. Tables 1 and 2). However, only due to the application of a minimum AF (i.e., 1), the derived $\mathrm{PNEC}_{\text {marine water }}$ for $\mathrm{ZnO}$ became more favorable compared to the organic UV filters 4MBC, BP3 and EHMC. However, in "reef safe" formulations the allowed concentration limit of $\mathrm{ZnO}$ is much higher (e.g., 25\%) compared to those of the organic UV filters (e.g., within EU max. 4, 6 and 10\% for 4MBC, BP3 and EHMC, respectively; Additional file 1: Table S1). Therefore, replacing some or even all organic UV filters from a certain sunscreen formulation by inorganics such as $\mathrm{ZnO}$, would certainly increase the concentration of such a UV filter in the aquatic environment. Thus, the term 'reef safe' may be regarded as controversial considering the known aquatic toxicity of $\mathrm{ZnO}$, its increasing release rates from the intensified use in 'reef safe' sunscreens and the absence of suitable environmental exposure calculation models. Furthermore, a recently developed evaluation tool, called EcoSun Pass combines both the intrinsic hazard profile of a UV filter and its efficacy to absorb UV light at the required wavelength to select the most ecofriendly and efficient UV filters for upcoming sunscreen formulations [63]. Thus, this tool may also help to reduce the amount of hazardous UV filters being released into the aquatic/marine environment.

To translate effect levels such as $\mathrm{EC}_{50}, \mathrm{EC}_{10}$ or NOEC values from single species tests under standardized laboratory conditions into a safe environmental concentration, the use of assessment factors is regarded as applicable [25]. Although the effect concentrations (e.g., NOECs) of various UV filters may be at a comparable concentration level, due to differences in the applied $\mathrm{AF}$, the resulting $\mathrm{PNEC}_{\text {marine }}$ water may be highly variable among the substances of concern. Nevertheless, it may also cover other species which have not been previously tested in such standardized toxicity tests. In other words, even if corals have not been considered in the hazard assessments, the observed toxicity levels from non-standardized toxicity tests may even be covered by the $\mathrm{PNEC}_{\text {marine water }}$ as retrieved from the corresponding REACH dossier of the substance. Our analysis indeed demonstrates that the observed LOECs from various coral toxicity tests were well within the derived PNECs for marine water, which were based on already available test results. Thus, they may not contribute to a significant change in these PNECs. However, it should be mentioned that the majority of the currently published coral toxicity data have several shortcomings with respect to assay design, which makes the interpretation of the results difficult and the conclusions drawn thereof questionable (see $[54,56])$. Due to the observed shortcomings and the lack of using validated testing methods, the use of such data as part of the hazard profiling of a substance is not recommended. Since corals are currently at high risk from several direct anthropogenic impacts such as untreated sewage discharge from coastal villages and cities, pesticides and personal care products (including sunscreens and UV filters within), further research is needed to include also coral toxicity data into regulatory toxicity testing programs for marine applications. To do so, we consider the development of standardized toxicity tests under the umbrella of ISO, CEN and/ or OECD as mandatory to allow for (1) a scientifically sound test results, (2) comparable assessments of substances and (3) mutual regulatory acceptance of test results. This standardization process may also include the selection of suitable and representative test coral species considered to be easily cultured and reproduced in aquaria or aquaculture facilities and thus preventing collections from wild populations. Similar to existing standardized OECD test guidelines for freshwater organisms, such standardized tests would require to cover both acute and chronic toxicity 
as well as effects on different coral life stages ranging from larvae to adults (see Moeller et al. [56] for detailed considerations for standardized coral toxicity tests). This process will certainly lead to a compromise (sensitivity versus sustainable culture) regarding the species of choice. However, testing a range of species using reference toxicants may also allow for the assessment of species-specific differences. This may also trigger the need for an additional AF to cover sensitive coral species, which, to this point, has not been tested. Results from those standardized tests may then be considered also as a suitable basis for a regulatory decision-making process. As such standardization processes are likely to take several years, a safety assessment for the marine compartment, including coral reefs, may be initiated by using existing effect data from available toxicity tests and applying appropriate AFs. Based on our initial assessment it can be concluded that the observed effects on corals are captured by the current $\mathrm{PNEC}_{\text {marine water }}$ as provided within individual REACH dossiers of the UV filters.

Furthermore, the 'reef safe' sunscreen terminology at its current state may even mislead consumers to extensive use of sunscreen and distract from alternative and important photoprotective measures. In addition to applying sunscreen to sun-exposed areas of the body, more emphasis should be given to educating the public on alternative ways of sun protection, namely, seeking shade when outdoors and using photoprotective clothing including rash guards, hats and sunglasses $[15,73,83,88$, 89]. Reducing the influx of sunscreen into reef environments should be emphasized in addition to decreasing their toxic effects towards corals. Even new formulations of sunscreens with lower toxicities to corals may still exert adverse effects to corals during periods of high usage. In this context, it should also be mentioned that apart from UV filters, sunscreens also contain a variety of other ingredients or co-formulants that largely consist of water, sensory enhancers, boosters/film formers, thickeners, emulsifiers and emollients $[61,66]$. Those coformulants aim for a sufficient product stability during both storage and use phase, and in addition allow for an easy application and good skin feeling [61]. Since co-formulants are released together with the UV filters into the marine environment during recreational activities, they may increase the bioavailability of the UV filters to corals and further exacerbate the toxicity of sunscreen products [35]. However, it should be taken into account, that physical effects by such co-formulants (i.e., increased water solubility of UV filters by the use of emulsifiers), is likely to occur in the formulation itself, where concentrations of such co-formulants are sufficiently high, but not necessarily in the marine environment where rapid dilution is likely to take place. Even though available toxicity data of co-formulants are suggesting these being less hazardous to the aquatic environment compared to UV filters [65], their potential to boost the bioavailability of active ingredients to corals should be further investigated.

\section{Conclusion}

To conclude, the substantial unequal treatment of organic and inorganic UV filters in political decision-making, as well as in the 'reef safe' sunscreen market is not scientifically justified leading to regulatory shortcomings in the decisions that have been taken by various states and thus requires adequate revisions. For future regulatory measures, we recommend and highly encourage a risk-based approach for each individual UV filter with equal consideration of both, organic and inorganic UV filters. Thus, the development of an appropriate internationally recognized and standardized ecotoxicological testing protocol for corals is required to allow for a comparable toxicity assessment of UV filters to best protect corals by the use of appropriate sunscreen compositions [56]. Besides this, the development of sophisticated environmental exposure models based on the application of UV filters in sunscreens is urgently needed in order to allow for a quantitative risk assessment for the marine compartment [63]. In this regard, regulatory requirements need to be put in place, especially for the USA where the number of available UV filters has been limited, despite the lack of a scientifically sound data basis and analysis. Finally, we stress the need to introduce a clear and scientifically sound criteria for the definition of a coral-/reef-safe terminology, besides efforts to reduce the overall influx of sunscreen products into reef environments.

\section{Abbreviations}

AF: Assessment factor; BCSA: Benzylidene camphor sulfonic acid; BEMT: Bis-ethylhexyloxyphenol methoxyphenyl triazine; BMDM: Butyl methoxydibenzoylmethane; BP: Benzophenone; CAS: Chemical Abstracts Service; CBM: Camphor benzalkonium methosulfate; CEN: European Committee for Standardization; DBT: Diethylhexyl butamido triazone; DHHB: Diethylamino hydroxybenzoyl hexyl benzoate; DMTO: Drometrizole trisiloxane; DPDT: Disodium phenyl dibenzimidazole tetrasulfonate; DTS: Drometrizole trisiloxane; EC: Effect concentration; ECHA: European Chemical Agency; EEMC: 2-Ethoxyethylp-methoxycinnamate; EHMC: Ethylhexyl methoxycinnamte; EHS: Ethylhexyl salicylate; EHT: Ethylhexyl triazone; ERA: Environmental exposure assessment; FAQ: Frequently asked questions; FDA: Food and Drug Administration; GHS: Globally Harmonized System; HMS: Homomethyl salicylate; INCI: International nomenclature of cosmetic ingredients; IPMC: Isoamyl p-methoxycinnamate; ISO: International Organization for Standardization; LC: Lethal concentration; LOEC: Lowest observed effect concentration; MA: Menthyl anthranilate; MBBT: Methylene bis-benzotriazolyl tetramethylbutylphenol; MBC: Methylbenzylidene camphor; MCHE: Methoxypropylamino cyclohexenylidene ethoxyethylcyanoacetate; NOEC: No observed effect concentration; OCR: Octocrylene; OECD: Organisation for Economic Co-operation and Development; OTC: Over the counter; PBC: Polyacrylamidomethyl benzylidene camphor; PBDT: Phenylene bis-diphenyltriazine; PBSA: Phenylbenzimidazole sulfonic acid; PCP: Personal care product; PNEC: Predicted no effect concentration; REACH: Registration, Evaluation, Authorisation and Restriction of Chemicals; SB: Senate bill; SCCS: Scientific Committee for Consumer Safety; SPF: Sun protection factor; SSD: Species sensitivity distribution; TBPT: Tris-biphenyl triazine; TDSA: Terephthalylidene dicamphor sulfonic acid; TEAS: 
Triethanolamine salicylate; USAN: United States adopted name; UV: Ultraviolet; WS: Water-solubility.

\section{Supplementary Information}

The online version contains supplementary material available at https://doi. org/10.1186/s12302-021-00515-w.

Additional file 1: Table S1. UV filters allowed in sunscreens in EU, USA and AUS and their current concentration limits. Table S2. List of products claimed to be reef safe (or similar), their active ingredients, and percentage.

\section{Acknowledgements}

We thank the two anonymous reviewers for their valuable and constructive comments. Their contribution greatly enhanced the quality of this article.

\section{Authors' contributions}

PJS, MM, SP and IBM designed the study. IBM and SP wrote the first draft of the manuscript. All authors read and approved the final manuscript.

\section{Funding}

The authors declare that this study received funding from BASF SE through the grant "Toxicity tests with corals and coral reef communities". Opinions expressed in the paper are those of the authors; the funder had no role in the study design, data collection, analysis or interpretation of the study findings.

\section{Availability of data and materials}

All data generated or analyzed during this study are included in this published article and its Additional files.

\section{Declarations}

\section{Ethics approval and consent to participate}

Not applicable.

\section{Consent for publication}

Not applicable.

\section{Competing interests}

MP-T and SP are employed by BASF SE. The remaining authors received either at least partial funding or project funds by BASF SE.

\section{Author details \\ ${ }^{1}$ Environmental Biochemistry Group, Institute for Chemistry and Biology of the Marine Environment (ICBM), Carl von Ossietzky University of Olden- burg, Schleusenstr. 1, 26382 Wilhelmshaven, Germany. ${ }^{2}$ BASF SE, GBP/RA, Z 570, Carl-Bosch-Str. 38, 67056 Ludwigshafen, Germany. ${ }^{3}$ BASF Personal Care and Nutrition GmbH, E-EMC/QR, Product Stewardship \& EHS Data Manage- ment, Rheinpromenade 1, 40789 Monheim, Germany. ${ }^{4}$ Helmholtz Institute for Functional Marine Biodiversity at the University of Oldenburg (HIFMB), Ammerländer Heerstr. 231, 26129 Oldenburg, Germany.}

\section{Received: 1 April 2021 Accepted: 12 June 2021}

Published online: 26 June 2021

\section{References}

1. AIMS (Australian Institute of Marine Science) (2020) Annual Summary Report on coral reef condition for 2019/2020. Initial recovery of the Great Barrier Reef threatened by the third mass bleaching event in five years. Townsville, Australia

2. Baker AC, Glynn PW, Riegl B (2008) Climate change and coral reef bleaching: an ecological assessment of long-term impacts, recovery trends and future outlook. Estuar Coast Shelf Sci 80:435-471. https://doi.org/10. 1016/j.ecss.2008.09.003
3. Bellwood DR, Hoey AS, Choat JH (2003) Limited functional redundancy in high diversity systems: resilience and ecosystem function on coral reefs. Ecol Lett 6:281-285. https://doi.org/10.1046/j.1461-0248.2003.00432.x

4. Bellwood DR, Hughes TP, Folke C, Nyström M (2004) Confronting the coral reef crisis. Nature 429:827-833. https://doi.org/10.1038/nature02691

5. Burke L, Reytar K, Spalding M, Perry A (2011) Reefs at Risk Revisited. World Resources Institute, The Nature Conservancy, WorldFish Center, International Coral Reef Action Network, UNEP World Conservation Monitoring Centre and Global Coral Reef Monitoring Network, Washington D.C.

6. Chisvert A, Salvador A (2007) UV filters in sunscreens and other cosmetics. regulatory aspects and analytical methods. In: Salvador A, Chisvert A (eds) Analysis of cosmetic products. Elsevier, Amsterdam, pp 83-120

7. City of Key West (2018) Ordinance 18-3253 ameding chapter 26 sunscreen. City Commission, Key West

8. Cole C, Shyr T, Ou-Yang H (2016) Metal oxide sunscreens protect skin by absorption, not by reflection or scattering. Photodermatol Photoimmunol Photomed 32:5-10. https://doi.org/10.1111/phpp.12214

9. Coral Reef Research Foundation (2017) Final Report Sunscreen Pollution Analysis in Jellyfish Lake Coral Reef Research Foundation Palau

10. Corinaldesi C, Marcellini F, Nepote E et al (2018) Impact of inorganic UV filters contained in sunscreen products on tropical stony corals (Acropora spp.). Sci Total Environ 637-638:1279-1285. https://doi.org/10.1016/j.scito tenv.2018.05.108

11. Cosmetics Europe (2021) The Cosmetic Industry and REACH. https:// cosmeticseurope.eu/cosmetics-industry/cosmetics-industry-and-reach/. Accessed 17 Mar 2021

12. Danovaro R, Bongiorni L, Corinaldesi C et al (2008) Sunscreens cause coral bleaching by promoting viral infections. Environ Health Perspect 116:441-447. https://doi.org/10.1289/ehp.10966

13. de Goeij JM, van Oevelen D, Vermeij MJA et al (2013) Surviving in a marine desert: the sponge loop retains resources within coral reefs. Science 342:108-110. https://doi.org/10.1126/science.1241981

14. Department of Nature and Environment (DNM) Aruba (2019) Environmental unfriendly products will be banned starting July 1, 2020. https:// www.government.aw/news/news_47033/item/environmental-unfri endly-products-will-be-banned-starting-july-1-2020_51844.html. Accessed 27 Jan 2021

15. Diffey B (2001) Sunscreen isn't enough. J Photochem Photobiol B Biol 64:105-108. https://doi.org/10.1016/S1011-1344(01)00195-6

16. Downs CA, Kramarsky-Winter E, Fauth JE et al (2014) Toxicological effects of the sunscreen UV filter, benzophenone-2, on planulae and in vitro cells of the coral, Stylophora pistillata. Ecotoxicology 23:175-191. https://doi. org/10.1007/s10646-013-1161-y

17. Downs CA, Kramarsky-Winter E, Segal R et al (2016) Toxicopathological effects of the sunscreen UV filter, oxybenzone (Benzophenone-3), on coral planulae and cultured primary cells and its environmental contamination in Hawaii and the U. S. Virgin Islands Arch Environ Contam Toxicol 70:265-288. https://doi.org/10.1007/s00244-015-0227-7

18. ECHA (2008) Guidance on information requirements and chmical safety assessment. Chapter R.10: Characterisation of dose [concentration]response for environment. Eur Chem Agency 1-65

19. ECHA (2020) Registration dossier - Zinc oxide. In: Reach Regist. Doss. https://echa.europa.eu/de/registration-dossier/-/registered-dossier/ 16139. Accessed 2 Feb 2021

20. ECHA (2021a) European Chemicals Agency (ECHA). https://echa.europa. eu/home. Accessed 30 Mar 2021

21. ECHA (2021b) The registration dossier. In: Reach Regist. Doss. https:// echa.europa.eu/regulations/reach/substance-registration/the-registrati on-dossier. Accessed 8 Mar 2021

22. ECHA (2021c) REACH Legislation. https://echa.europa.eu/regulations/ reach/legislation. Accessed 17 Mar 2021

23. Ecosia (2021) Ecosia. https://www.ecosia.org/. Accessed 11 Mar 2021

24. European Commission (2009) Annex VI List of UV Filters allowed in Cosmetic Products. Regulation (EC) No 1223/2009 of the European Parliament and of the Council of 30 November 2009 on cosmetic products. In: EUR-Lex. Access to Eur. Union law

25. European Commission (2003) Technical Guidance Document on Risk Assessment. TGD Part II 337

26. European Union (2009) Regulation (EC) No 1107/2009 of The European Parliament and of the Council of 21 October 2009 concerning the placing of plant protection products on the market and repealing Council 
Directives 79/117/EEC and 91/414/EEC. In: Off. J. Eur. Union. http://eurlex.europa.eu/LexUriServ/LexUriServ.do?uri=OJ:L:2009:309:0001:0050: en:PDF. Accessed 17 Mar 2021

27. European Union (2012) Regulation (EU) No 524/2013 of the European Parliament and of the Council of 22 May 2012 concerning the making available on the market and use of biocidal products. In: Off. J. Eur. Union

28. Fel J-P, Lacherez C, Bensetra A et al (2019) Photochemical response of the scleractinian coral Stylophora pistillata to some sunscreen ingredients. Coral Reefs 38:109-122. https://doi.org/10.1007/ s00338-018-01759-4

29. Florida League of Cities (2020) 2020 Legislative Session. Final Report

30. Giokas DL, Salvador A, Chisvert A (2007) UV filters: from sunscreens to human body and the environment. TrAC Trends Anal Chem 26:360-374. https://doi.org/10.1016/j.trac.2007.02.012

31. Google (2021) Google. https://www.google.com/. Accessed 11 Mar 2021

32. Graham NAJ, Jennings S, MacNeil MA et al (2015) Predicting climatedriven regime shifts versus rebound potential in coral reefs. Nature 518:94-97. https://doi.org/10.1038/nature14140

33. Hawaii (2018) SB2571. https://www.capitol.hawaii.gov/session2018/bills/ SB2571_HTM. Accessed 19 Jun 2020

34. He K, Hain E, Timm A et al (2019) Occurrence of antibiotics, estrogenic hormones, and UV-filters in water, sediment, and oyster tissue from the Chesapeake Bay. Sci Total Environ 650:3101-3109. https://doi.org/10. 1016/j.scitotenv.2018.10.021

35. He T, Tsui MMP, Tan CJ et al (2019) Toxicological effects of two organic ultraviolet filters and a related commercial sunscreen product in adult corals. Environ Pollut 245:462-471. https://doi.org/10.1016/j.envpol.2018. 11.029

36. HeT, Tsui MMP, Tan CJ et al (2019) Comparative toxicities of four benzophenone ultraviolet filters to two life stages of two coral species. Sci Total Environ 651:2391-2399. https://doi.org/10.1016/j.scitotenv.2018.10.148

37. Heron SF, Maynard JA, Van Hooidonk R, Eakin CM (2016) Warming trends and bleaching stress of the world's coral reefs 1985-2012. Sci Rep 6:1-14. https://doi.org/10.1038/srep38402

38. Herzog B (2012) Photoprotection of human skin. In: Albini A, Fasani E (eds) Photochemistry. The Royal Society of Chemistry, pp 245-273

39. Herzog B, Sengün F (2015) Scattering particles increase absorbance of dyes-a model study with relevance for sunscreens. Photochem Photobiol Sci 14:2054-2063. https://doi.org/10.1039/c5pp00109a

40. Hoegh-Guldberg O (1999) Climate change, coral bleaching and the future of the world's coral reefs. Mar Freshw Res 50:839-866. https://doi. org/10.1071/MF99078

41. Hoegh-Guldberg O, Mumby PJ, Hooten AJ et al (2007) Coral reefs under rapid climate change and ocean acidification. Science 318:1737-1742. https://doi.org/10.1126/science.1152509

42. Hoegh-Guldberg O, Poloczanska ES, Skirving W, Dove S (2017) Coral reef ecosystems under climate change and ocean acidification. Front Mar Sci. https://doi.org/10.3389/fmars.2017.00158

43. Hughes TP, Anderson KD, Connolly SR et al (2018) Spatial and temporal patterns of mass bleaching of corals in the Anthropocene. Science 359:80-83. https://doi.org/10.1126/science.aan8048

44. Hughes TP, Baird AH, Bellwood DR et al (2003) Climate change, human impacts, and the resilience of coral reefs. Science 301:929-933. https:// doi.org/10.1126/science.1085046

45. Hughes TP, Barnes ML, Bellwood DR et al (2017) Coral reefs in the Anthropocene. Nature 546:82-90. https://doi.org/10.1038/nature22901

46. Hughes TP, Graham NAJ, Jackson JBC et al (2010) Rising to the challenge of sustaining coral reef resilience. Trends Ecol Evol 25:633-642. https:// doi.org/10.1016/j.tree.2010.07.011

47. Hughes TP, Kerry JT, Álvarez-Noriega M et al (2017) Global warming and recurrent mass bleaching of corals. Nature 543:373-377. https://doi.org/ 10.1038/nature21707

48. Hughes TP, Linares C, Dakos V et al (2013) Living dangerously on borrowed time during slow, unrecognized regime shifts. Trends Ecol Evol 28:149-155. https://doi.org/10.1016/j.tree.2012.08.022

49. IPCC (2015) Climate Change 2014: Synthesis Report. Contribution of Working Groups I, II and III to the Fifth Assessment Report of the Intergovernmental Panel on Climate Change. IPCC, Geneva, Switzerland

50. Levine A (2020) Sunscreen use and awareness of chemical toxicity among beach goers in Hawaii prior to a ban on the sale of sunscreens containing ingredients found to be toxic to coral reef ecosystems. Mar Policy 117:103875. https://doi.org/10.1016/..marpol.2020.103875

51. McCoshum SM, Schlarb AM, Baum KA (2016) Direct and indirect effects of sunscreen exposure for reef biota. Hydrobiologia 776:139-146. https:// doi.org/10.1007/s10750-016-2746-2

52. metaGer (2021) metaGer. https://metager.org/. Accessed 11 Mar 2021

53. Ministry of Spatial Development Aruba (2019) Afkondigingsblad van Aruba 2019 no. 67

54. Mitchelmore CL, Burns EE, Conway A et al (2021) A critical review of organic ultraviolet filter exposure, hazard, and risk to corals. Environ Toxicol Chem 40:967-988. https://doi.org/10.1002/etc.4948

55. Moberg F, Folke C (1999) Ecological goods and services of coral reef ecosystems. Ecol Econ 29:215-233. https://doi.org/10.1016/S0921-8009(99) 00009-9

56. Moeller M, Pawlowski S, Petersen-Thiery M et al (2021) Challenges in current coral reef protection - possible impacts of uv filters used in sunscreens, a critical review. Front Mar Sci. https://doi.org/10.3389/fmars. 2021.665548

57. Narla S, Lim HW (2020) Sunscreen: FDA regulation, and environmental and health impact. Photochem Photobiol Sci 19:66-70. https://doi.org/ 10.1039/c9pp00366e

58. NLM National Library of Medicine (2021) DailyMed database. In: Natl. Institutes Heal. https://dailymed.nlm.nih.gov/dailymed/. Accessed 10 Mar 2021

59. OECD (2019) Guidance Document on Aquatic Toxicity Testing of Difficult Substances and Mixtures. Series on Testing and Assessment No. 23 (2nd edition). Organ Econ Co-operation Dev 23:1-81

60. OECD (2006) Current approaches in the statistical analysis of ecotoxicity data: a guidance to application. OECD Environ Heal Saf Publ - Ser Test Assess No 54(54):1-147

61. Osterwalder U, Sohn M, Herzog B (2014) Global state of sunscreens. Photodermatol Photoimmunol Photomed 30:62-80. https://doi.org/10. 1111/phpp.12112

62. Ouchene L, Litvinov IV, Netchiporouk E (2019) Hawaii and other jurisdictions ban oxybenzone or octinoxate sunscreens based on the confirmed adverse environmental effects of sunscreen ingredients on aquatic environments. J Cutan Med Surg 23:648-649. https://doi.org/10.1177/ 1203475419871592

63. Pawlowski S, Herzog B, Sohn M et al (2020) EcoSun Pass: a tool to evaluate the ecofriendliness of UV filters used in sunscreen products. Int J Cosmet Sci. https://doi.org/10.1111/ics.12681

64. Pawlowski S, Lanzinger AC, Dolich T et al (2019) Evaluation of the bioaccumulation of octocrylene after dietary and aqueous exposure. Sci Total Environ 672:669-679. https://doi.org/10.1016/j.scitotenv.2019.03.237

65. Pawlowski S, Moeller M, Miller IB et al (2021) UV filter used in sunscreens - a lack in current coral protection? Integr Environ Assess Manag. https:// doi.org/10.1002/ieam.4454

66. Pawlowski S, Petersen-Thiery M (2020) Sustainable sunscreens: a challenge between performance, animal testing ban, and human and environmental safety. Handb Environ Chem 94:185-207. https://doi.org/ $10.1007 / 698 \quad 2019 \quad 444$

67. Piella J, Bastús NG, Casals E, Puntes V (2013) Characterizing nanoparticles reactivity: structure-photocatalytic activity relationship. J Phys Conf Ser. https://doi.org/10.1088/1742-6596/429/1/012040

68. Rädecker N, Pogoreutz C, Voolstra CR et al (2015) Nitrogen cycling in corals: the key to understanding holobiont functioning? Trends Microbiol 23:490-497. https://doi.org/10.1016/j.tim.2015.03.008

69. Republic of Palau (2018) Senate Bill No. 10-135, SD1, HD1 (The Responsible Tourism Education Act of 2018)

70. Roff G, Mumby PJ (2012) Global disparity in the resilience of coral reefs. Trends Ecol Evol 27:404-413. https://doi.org/10.1016/j.tree.2012.04.007

71. Rougerie F, Wauthy B (1993) The endo-upwelling concept: from geothermal convection to reef construction. Coral Reefs 12:19-30. https://doi. org/10.1007/BF00303781

72. Scheffer M, Barrett S, Carpenter SR et al (2015) Creating a safe operating space for iconic ecosystems: manage local stressors to promote resilience to global change. Science 347:1317-1319. https://doi.org/10.1126/scien ce.aaa3769

73. Schneider SL, Lim HW (2019) Review of environmental effects of oxybenzone and other sunscreen active ingredients. J Am Acad Dermatol 80:266-271. https://doi.org/10.1016/j.jaad.2018.06.033 
74. Sharifan $\mathrm{H}$ (2020) Alarming the impacts of the organic and inorganic UV blockers on endangered coral's species in the Persian Gulf: a scientific concern for coral protection. Sustain Futur 2:100017. https://doi.org/10 1016/j.sftr.2020.100017

75. Sohn M, Krus S, Schnyder M et al (2020) How to overcome the new challenges in sun care. Sofw 146:2-10

76. Spalding D, Ravilious C (2002) World atlas of coral reefs

77. Spalding MD, Grenfell AM (1997) New estimates of global and regional coral reef areas. Coral Reefs 16:225-230. https://doi.org/10.1007/s0033 80050078

78. Stien D, Clergeaud F, Rodrigues AMS et al (2019) Metabolomics reveal that octocrylene accumulates in Pocillopora damicornis tissues as fatty acid conjugates and triggers coral cell mitochondrial dysfunction. Anal Chem 91:990-995. https://doi.org/10.1021/acs.analchem.8b04187

79. Stien D, Suzuki M, Rodrigues AMS et al (2020) A unique approach to monitor stress in coral exposed to emerging pollutants. Sci Rep 10:1-12. https://doi.org/10.1038/s41598-020-66117-3

80. The Florida Senate (2020) Chapter 2020-118. Senate Bill No. 172: Florida Drug and Cosmetic Act. Legislature of the State of Florida

81. United Nations (2019) GHS (Rev.8) (2019). Globally Harmonized System of Classification and Labelling of Chemicals (GHS). https://unece.org/ghsrev8-2019. Accessed 17 Mar 2021

82. US Congress (2014) Public Law 113 - 79 113th Congress An Act. Sunscreen Innovation Act. 1-357

83. US Department of Health and Human Services (2014) The Surgeon General's Call to Action to Prevent Skin Cancer. 22

84. US Food and Drug Administration (2011) 21 CFR Parts 201 and 310 Labeling and Effectiveness Testing; Sunscreen Drug Products for
Over-the- Counter Human Use Federal Register/ Vol. 76, No. 117/Friday, June 17, 2011. 76:35678-35681

85. US Food and Drug Administration (2019) Sunscreen drug products for over-the-counter human use: proposed rule. Fed Regist 84:6204-6275

86. US Virgin Islands (2019) AJfNO. 8185. Bill No. 33-0043. Thirty-Third Legislature of the Virgin Islands. Regular Session 2019. Virgin Islands

87. van de Leemput IA, Hughes TP, van Nes EH, Scheffer M (2016) Multiple feedbacks and the prevalence of alternate stable states on coral reefs. Coral Reefs 35:857-865. https://doi.org/10.1007/s00338-016-1439-7

88. Walkosz BJ, Scott MD, Buller DB et al (2017) Prevalence of sun protection at outdoor recreation and leisure venues at resorts in North America. Am J Heal Educ 48:90-99. https://doi.org/10.1080/19325037.2016.1271755

89. WHO (2002) Global Solar UV Index: a Practical Guide. In: UN Environ. Program. https://www.unep.org/resources/report/global-solar-uv-indexpractical-guide\#: :text=The Global Solar UV Index,level at the Earth's surface. Accessed 21 May 2021

90. Wijgerde T, van Ballegooijen M, Nijland R et al (2020) Adding insult to injury: effects of chronic oxybenzone exposure and elevated temperature on two reef-building corals. Sci Total Environ 733:139030. https://doi.org/ 10.1016/j.scitotenv.2020.139030

\section{Publisher's Note}

Springer Nature remains neutral with regard to jurisdictional claims in published maps and institutional affiliations.

\section{Submit your manuscript to a SpringerOpen ${ }^{\circ}$ journal and benefit from:}

- Convenient online submission

- Rigorous peer review

- Open access: articles freely available online

- High visibility within the field

- Retaining the copyright to your article

Submit your next manuscript at $\boldsymbol{\nabla}$ springeropen.com 